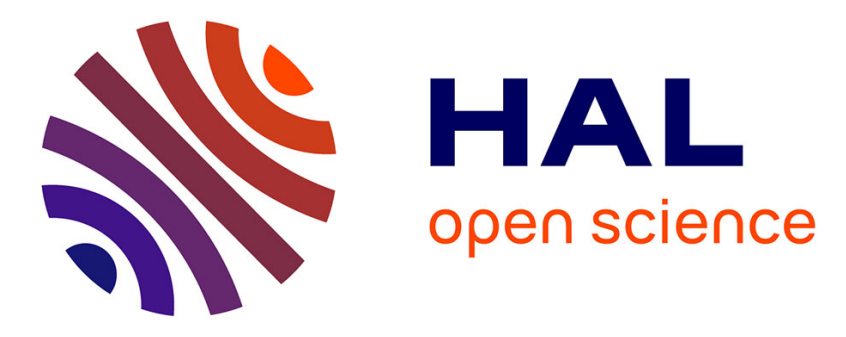

\title{
2-D Analytical Model of Conventional Switched Reluctance Machines
}

Walid Belguerras, Youcef Benmessaoud, Frédéric Dubas, Kamel Boughrara, Mickaël Hilairet

\section{- To cite this version:}

Walid Belguerras, Youcef Benmessaoud, Frédéric Dubas, Kamel Boughrara, Mickaël Hilairet. 2D Analytical Model of Conventional Switched Reluctance Machines. ELECTRIMACS, May 2019, Salerno, Italy. hal-02300492

\section{HAL Id: hal-02300492 https://hal.science/hal-02300492}

Submitted on 29 Sep 2019

HAL is a multi-disciplinary open access archive for the deposit and dissemination of scientific research documents, whether they are published or not. The documents may come from teaching and research institutions in France or abroad, or from public or private research centers.
L'archive ouverte pluridisciplinaire HAL, est destinée au dépôt et à la diffusion de documents scientifiques de niveau recherche, publiés ou non, émanant des établissements d'enseignement et de recherche français ou étrangers, des laboratoires publics ou privés. 


\title{
2-D Analytical Model of Conventional Switched Reluctance Machines
}

\author{
Walid Belguerras Youcef Benmessaoud Fréderic Dubas Kamel Boughrara Mickael Hilairet
}

\begin{abstract}
In this paper, we present a two-dimensional (2-D) analytical model of a conventional switched reluctance machines (SRMs). This model has been applied to a $8 / 6$ conventional SRM supplied by conventional excitation (viz., standard asymmetric H-bridge). The goal is to determine the electromagnetic performances. The proposed analytical model is based on solving the partial differential equations (PDEs) due to Maxwell's equations in each domain of the studied machine (viz., air-gap, rotor and stator slots). A parametric study by using the developed analytical model has been compared with that obtained by numerical computations in linear and no-linear conditions. The results showed that the analytical and numerical results are in good agreements in linear conditions. However, in no-linear conditions, the developed model over-estimates the performances. Indeed, to pre-design the machine, this model can be incorporated in optimization environments where savings in computation time are needed.
\end{abstract}

\section{Introduction}

The SRMs present many benefits for high-speed applications (e.g., electric compressor) compared with other types of machines. It can be operated at a very high-speed because it has no sliding contacts $[1,2]$, and can be operate in sever conditions of temperatures. It is a competitor of a permanentmagnet synchronous machines for electric vehicle

\author{
W. Belguerras Y.Benmessaoud F. Dubas M. Hilairet \\ FEMTO-ST, CNRS, Univ. Bourgogne Franche-Comté \\ Rue Thierry Mieg \\ F-90010 Belfort Cedex, France \\ walid.belguerras@femto-st.fr, \\ youcef.benmessaoud@gmail.com \\ FDubas@gmail.com, \\ mickael.hilairet@univ-fcomte.fr \\ K. Boughrara \\ Ecole Nationale Polytechnique (LRE-ENP) \\ Rue des Frères Oudek \\ Hassan Badi, B.P. 182, El-Harrach, 16200, Alger, Algérie \\ kamel.boughrara@g.enp.edu.dz
}

applications because of its simplicity and low cost, and its ability to operate at high-speed with low maintenance [3-5]. In the literature, we find different methods of electromagnetic modeling of electric machines; semi-analytical modeling based on the magnetic equivalent circuit (or permeance network) [6, 7], subdomain method in linear conditions (i.e., infinite permeability of the iron parts) [8-10], and the exact subdomain method taken into account the iron permeability [11-15]. In addition, we find analytical methods based on multi-layers [16-19] or elementary subdomains for the local saturation effect [20-21].

The analytical methods cited previously give an accurate electromagnetic result compared with numerical calculations, with reduced computation time. In this paper, we will present a comparison study of 2-D electromagnetic performances between the developed linear model based on the subdomain method in linear conditions. In order to analyse the validity of the developed model, the results has been compared with those computed numerically using FEMM [22] in linear and no-linear conditions.

\section{Analytical model}

The analytical model based on the subdomain method in linear conditions is given in [8-10]. In order to simplify the model, we have considered the following assumptions:

- $\quad$ End-effects are neglected, i.e., $\boldsymbol{A}=\left\{0 ; 0 ; A_{z}\right\}$;

- Eddy-currents effects in all materials are neglected;

- Current density in the stator slots has only on component along the z-axis, i.e., $J=\left\{0 ; 0 ; J_{z}\right\}$;

- $\quad$ The slots have a radial sides;

- The relative permeability is considered infinite for the iron parts (i.e., the saturation effect is neglected).

The schematic representation of the studied $8 / 6$ conventional SRM is shown in Fig. 1.

In developing the 2D analytical model, a magnetic vector potential formulation is used in polar coordinates. It consists of solving the partial differential equation [23] due to 


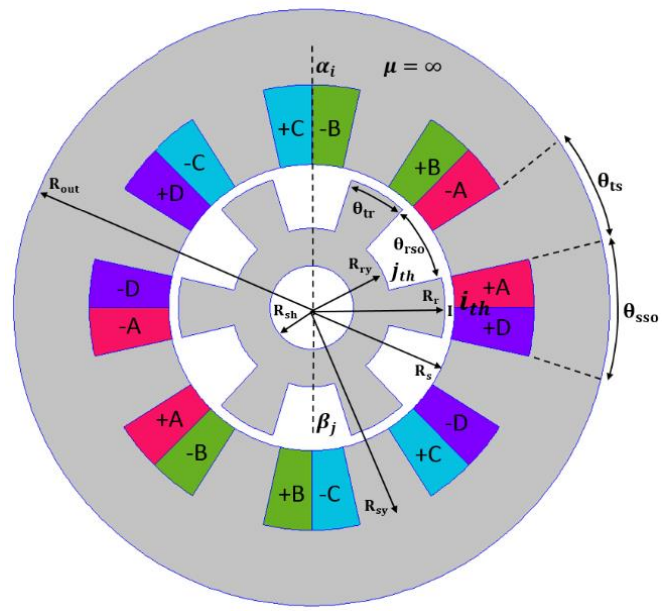

Fig. 1 Example of $8 / 6$ conventional SRM.

Table 1 Parameters of $8 / 6$ conventional SRM

\begin{tabular}{lll}
\hline \hline Parameter & Value \\
\hline \hline $\mathrm{Q}_{\mathrm{s}}$ & Number of stator slots & 8 \\
\hline $\mathrm{Q}_{\mathrm{r}}$ & Number of rotor slots & 6 \\
\hline $\mathrm{R}_{\mathrm{sh}}$ & Radius of the shaft & $11.5 \mathrm{~mm}$ \\
\hline $\mathrm{R}_{\mathrm{ry}}$ & Radius of the rotor yoke & $20.9 \mathrm{~mm}$ \\
\hline $\mathrm{R}_{\mathrm{r}}$ & Radius of the rotor surface & $33.9 \mathrm{~mm}$ \\
\hline $\mathrm{R}_{\mathrm{s}}$ & The stator bore radius & $43 \mathrm{~mm}$ \\
\hline $\mathrm{R}_{\mathrm{sy}}$ & Radius of the stator yoke & $53.4 \mathrm{~mm}$ \\
\hline $\mathrm{R}_{\mathrm{out}}$ & Outer radius of the stator & $71.5 \mathrm{~mm}$ \\
\hline $\mathrm{L}$ & Axial length & $125 \mathrm{~mm}$ \\
\hline$\theta_{S s o}$ & Stator slot opening & $25.2^{\circ}$ \\
\hline$\theta_{w}$ & Opening of a slot coil & $12.6^{\circ}$ \\
\hline$\theta_{\mathrm{ts}}$ & Stator teeth opening & $19.8^{\circ}$ \\
\hline$\theta_{\mathrm{rso}}$ & Rotor slot opening & $39.3^{\circ}$ \\
\hline$\theta_{\mathrm{tr}}$ & Rotor teeth opening & $20.6^{\circ}$ \\
\hline $\mathrm{N}$ & Number of harmonic in air-gap & 150 \\
\hline $\mathrm{M}$ & Number of harmonic in rotor slots & 150 \\
\hline $\mathrm{K}$ & Number of harmonic in stator slots & 150 \\
\hline $\mathrm{P}$ & Pitch used in calculation & $12^{\circ}$ \\
\hline \hline
\end{tabular}

Maxwell's equations in each domain of the studied machine. The equations to be solved in each region are given by

$$
\begin{aligned}
& \frac{\partial^{2} A_{z I}}{\partial r^{2}}+\frac{1}{r} \cdot \frac{\partial A_{z I}}{\partial r}+\frac{1}{r^{2}} \cdot \frac{\partial^{2} A_{z I}}{\partial \theta^{2}}=0(\text { Region } I), \\
& \frac{\partial^{2} A_{z j}}{\partial r^{2}}+\frac{1}{r} \cdot \frac{\partial A_{z j}}{\partial r}+\frac{1}{r^{2}} \cdot \frac{\partial^{2} A_{z j}}{\partial \theta^{2}}=0\left(\text { Region } j^{t h}\right) . \\
& \frac{\partial^{2} A_{z i}}{\partial r^{2}}+\frac{1}{r} \cdot \frac{\partial A_{z i}}{\partial r}+\frac{1}{r^{2}} \cdot \frac{\partial^{2} A_{z i}}{\partial \theta^{2}}=-\mu_{0} \cdot J_{z i}\left(\text { Region } i^{t h}\right) .
\end{aligned}
$$

Solving of PDEs given by (1) allows to obtain the general solution of $A_{z}$ in each domain [8-10]. The integration constants are determined by using a Fourier series expansion of $A_{z}$ in each region and the boundary conditions (BCs) [8-21]. The linear systeme can be written as

$$
[A] \cdot[X]=[B]
$$

where:

- $\quad[A]$ is the square matrix of the integration constants obtained by BCs of dimension $Q \times Q$ with $Q=4 N+Q_{r} \cdot(1+M)+Q_{s} \cdot(1+K)$ in which $Q_{s} \& Q_{r}$ represents respectively number of the stator and rotor slots, and $N, M \& K$ represents respectively the finite number of spatial harmonics terms in various regions;

- $\quad[X]$ is the vector of unknowns (integration constants to determine) with dimension $Q \times 1$;

- $\quad[B]$ is the vector of electromagnetic sources terms with dimension $Q \times 1$.

The vector $[X]$ can divided in 3 parts as following:

- $\quad$ Part 1 is air-gap (i.e., Region I) with dimension $4 N \times 1$;

- $\quad$ Part 2 is the rotor slots (i.e., Region $j^{\text {th }}$ ) with dimension $Q_{r} \cdot(1+M) \times 1$;

- $\quad$ Part 3 is the stator slots (i.e., Region $i^{\text {th }}$ ) with dimension $Q_{s} \cdot(1+K) \times 1$.

Using the geometrical and physical parameters given in Table 1, we have calculated the computing time necessary for obtaining the vector $[X]$ (viz., $\mathrm{t}=58.85 \mathrm{~s}$ for 31 position), and the computing time necessary for making the mesh and analyse on FEMM (viz., $\mathrm{t}=151.33 \mathrm{~s}$ for 31 positions. The auto-mesh is used).

\section{Simulation results}

The analytical expression of electromagnetic torque and the method for calculating the flux are given in [9, 10, 13-21]. We have used the parameters of SRM given in [24] for our comparison study.

Fig. 2 shows the equipotential lines of $A_{z}$ in the machine due to phase $\mathrm{A}\left(\mathrm{I}_{\mathrm{A}}=20 \mathrm{~A}\right)$ at $180^{\circ}$ rotor position obtained by numerical model. Fig. 3 shows the radial and tangential magnetic flux density in the middle of the air-gap by feeding only phase $\mathrm{A}(\mathrm{I}=10 \mathrm{~A})$ for rotor position $45^{\circ}$.

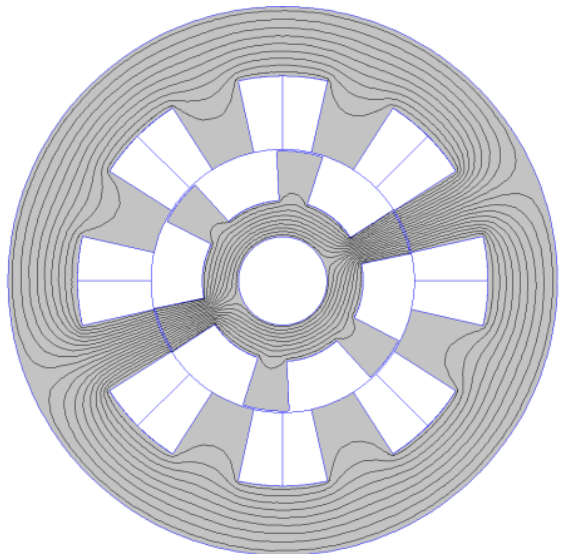

Fig. 2 Equipotential lines of $A_{z}$ due to phase $\mathrm{A}$ for $\mathrm{I}_{\mathrm{A}}=20 \mathrm{~A}$ and $180^{\circ}$ rotor position. 


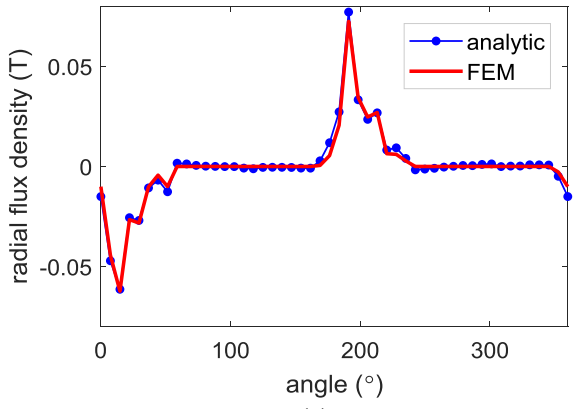

(a)

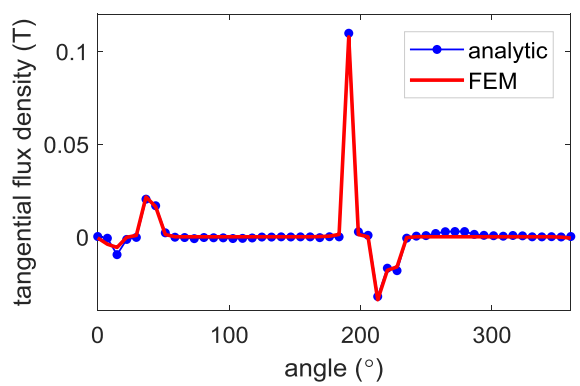

(b)

Fig. 3 Radial (a) and tangential (b) components of magnetic flux density in the air-gap for $\mathrm{I}_{\mathrm{A}}=10 \mathrm{~A}$ and rotor position $45^{\circ}$.

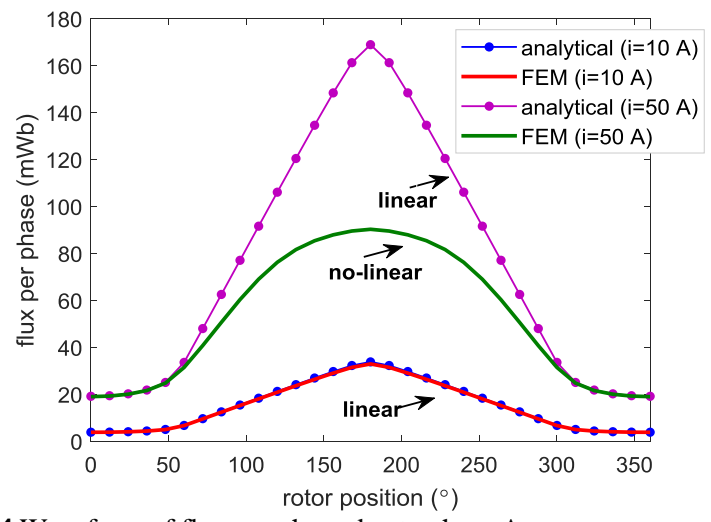

Fig. 4 Waveform of flux per phase due to phase A.

Fig. 4 shows a comparison between the numerical and analytical result of flux per phase due to phase A. In linear $(\mathrm{I}=10 \mathrm{~A})$, the numerical and analytical results are in well agreement. In no-linear, the relative error between analytical and numerical results is $46.56 \%$. The mutual flux between phase A and others phases is shown in Fig. 5. In no-linear, the analytical and numerical results present the $49.12 \%$ relative error. The mutual flux between phases A-C is null because the opening between this phases is $\pi / 2$.

Fig. 6 shows the comparison between analytical and numerical results of static electromagnetic torque due to phase A. It can be seen that the analytical model gives the accurate results in linear. In no-linear, we have a $42.15 \%$ relative error between the analytical and numerical results. This important relative error due to no considering the relative permeability of iron parts in the analytical model.

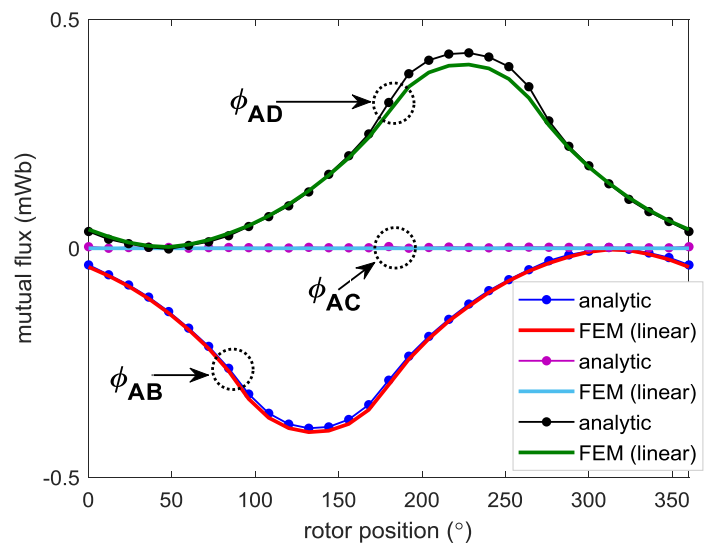

(a)

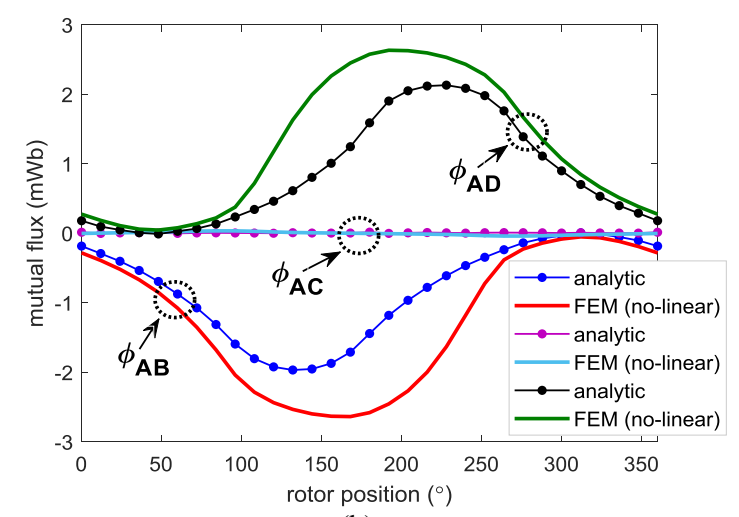

(b)

Fig. 5 Waveform of mutual flux obtained by feeding phase A in: (a) linear $\left(\mathrm{I}_{\mathrm{A}}=10 \mathrm{~A}\right)$, and $(\mathrm{b})$ no-linear $\left(\mathrm{I}_{\mathrm{A}}=50 \mathrm{~A}\right)$.

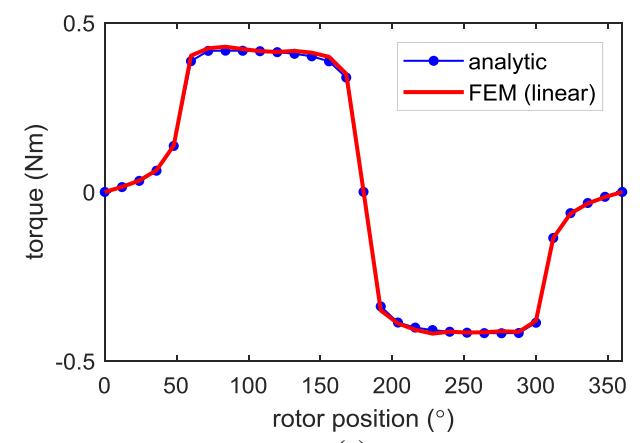

(a)

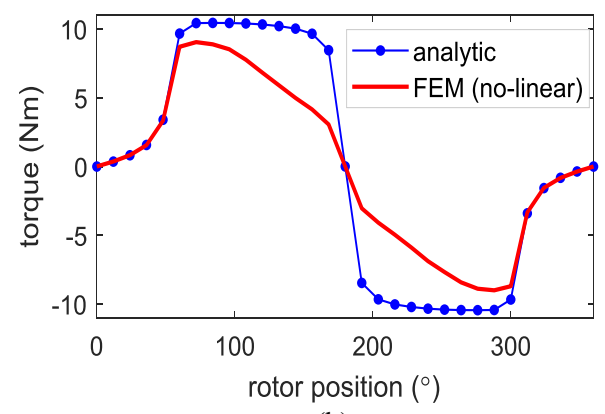

(b)

Fig. 6 Waveform of the static electromagnetic torque due to phase A in: (a) linear $\left(\mathrm{I}_{\mathrm{A}}=10 \mathrm{~A}\right)$, and (b) no-linear $\left(\mathrm{I}_{\mathrm{A}}=50 \mathrm{~A}\right)$. 


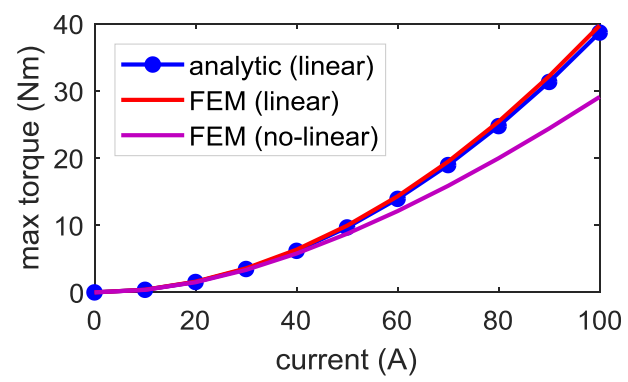

Fig. 7 The maximum electromagnetic torque due to phase $\mathrm{A}$ for different values of current

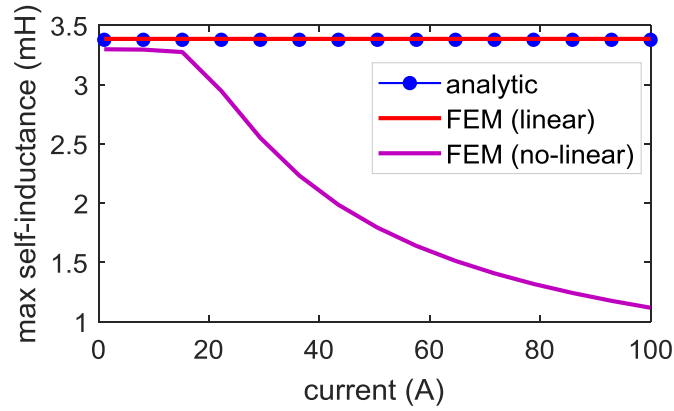

Fig. 8 The maximum self-inductance due to phase A for different values of current.

Fig. 7 shows the comparison between analytical model and (no-)linear numerical results of the maximum electromagnetic torque due to phase A for different values of current (0-100 A). The results of the max self-inductance due to phase A for different values of current (0-100 A) obtained by analytical model, and (no-)linear numerical model are shown in Fig. 8. It can be seen that the analytical model gives a good results with no-linear numerical result in limited current rang ( $\leq 30 \mathrm{~A}$ for max torque, and $\mathrm{I} \leq 20 \mathrm{~A}$ for $\max$ self-inductance).

\section{Conclusion}

In this paper, we have presented an analytical model based on the subdomain method of $8 / 6$ conventional SRM in linear conditions. The analytical results are in excellent agreement with numerical ones. However, in no-linear conditions ( $I=50$ A), the developed model overestimates the electromagnetic performances with a maximum error of about $46 \%$. However, by taking into account this error, this model can be usefully used in optimization procedure where saving of computation time is required. In order to obtain more accurate performances in no-linear conditions, this model can be extended to the saturation case (taking into account the characteristic of relative permeability of iron parts). It will be the object of our future works.

\section{References}

1. C. Gong and T. Habetler, "A novel rotor design for ultra-high speed switched reluctance machines over 1 million rpm," in 2017 IEEE International Electric Machines and Drives Conference (IEMDC), 2017, pp. 1-6.
2. P. T. Hieu, D. Lee, and J. Ahn, "Design of a high speed $4 / 2$ switched reluctance motor for blender application," in 2017 IEEE Transportation Electrification Conference and Expo, AsiaPacific (ITEC Asia-Pacific), 2017, pp. 1-5.

3. M. Takeno, A. Chiba, N. Hoshi, S. Ogasawara, M. Takemoto, and A. Rahman, "Test Results and torque improvement of the 50-kW switched reluctance motor designed for hybrid electrical vehicles," IEEE Trans. Ind. Appl., vol. 48, no. 4, pp. 1327-1334, Jul.-Aug. 2012.

4. X. Rain, "Contributions à la commande et à la conception des machines à réluctance variable à double saillance," thesis, Paris 11, 2013.

5. M.-W. Arab, "Étude et conception d'un groupe motopropulseur électrique à faibles niveau vibratoire et sonore pour véhicule électrique. Aspects 'contrôle - commande,"” thesis, Paris 11, 2015.

6. R. Benlamine, F. Dubas, S. Randi, D. Lhotellier, and C. Espanet, "Modeling of an axial-flux interior PMs machine for an automotive application using magnetic equivalent circuit," in 2015 18th International Conference on Electrical Machines and Systems (ICEMS), 2015, pp. 1266-1271.

7. R. Benlamine, Y. Benmessaoud, F. Dubas, and C. Espanet, "Nonlinear Adaptive Magnetic Equivalent Circuit of a RadialFlux Interior Permanent-Magnet Machine Using Air-Gap Sliding-Line Technic," in 2017 IEEE Vehicle Power and Propulsion Conference (VPPC), 2017, pp. 1-6.

8. F. Dubas, C. Espanet, "Analytical Solution of the Magnetic Field in Permanent-Magnet Motors Taking Into Account Slotting Effect: No-load Vector Potential and Flux Density Calculation," IEEE Trans. Magn., vol. 45, no. 5, pp. 2097-2109, May 2009.

9. T. Lubin, S. Mezani, and A. Rezzoug, "2-D Exact Analytical Model for Surface-Mounted Permanent-Magnet Motors With Semi-Closed Slots," IEEE Trans. Magn., vol. 47, no. 2, pp. 479492, Feb. 2011

10. T. Lubin, S. Mezani, and A. Rezzoug, "Exact Analytical Method for Magnetic Field Computation in the Air Gap of Cylindrical Electrical Machines Considering Slotting Effects," IEEE Trans. Magn., vol. 46, no. 4, pp. 1092-1099, Apr. 2010.

11. F. Dubas and K. Boughrara, "New Scientific Contribution on the 2-D Subdomain Technique in Cartesian Coordinates: Taking into Account of Iron Parts," Math. Comput. Appl., vol. 22, no. 1, p. 17, Feb. 2017.

12. F. Dubas and K. Boughrara, "New Scientific Contribution on the 2-D Subdomain Technique in Polar Coordinates: Taking into Account of Iron Parts," Math. Comput. Appl., vol. 22, no. 4, p. 42, Oct. 2017.

13. L. Roubache, K. Boughrara, F. Dubas, and R. Ibtiouen, "New Subdomain Technique for Electromagnetic Performances Calculation in Radial-Flux Electrical Machines Considering Finite Soft-Magnetic Material Permeability," IEEE Trans. Magn., vol. 54, no. 4, Art. ID 8103315, Apr. 2018.

14. M. Ben Yahia, L Roubache, Z. Djelloul-Khedda, K. Boughrara, F. Dubas, and R. Ibtiouen, "A 2-D Exact Subdomain Technique in Switched Reluctance Machines Taking Into Account of Finite Soft-Magnetic Material Permeability," in 2018 International Conference on Electrical Sciences and Technologies in Maghreb (CISTEM), 2018, pp. 557-562.

15. M. Ben Yahia, K. Boughrara, F. Dubas, L. Roubache, and R. Ibtiouen, "Two-Dimensonal Exact Subdomain Technique of Switched Reluctance Machines with Sinusoidal Current Excitation," Math. Comput. Appl., vol. 23, no. 4, p. 59, Oct.. 2018.

16. R.L.J. Sprangers, J.J.H. Paulides, B.L.J. Gysen, J. Waarma, and E.A. Lomonova, "Semi-Analytical Framework for Synchronous Reluctance Motor Analysis Including Finite Soft-Magnetic Material Permeability," IEEE Trans. Magn., vol. 51, no. 11, Art. ID 8110504, Nov. 2015.

17. R.L.J. Sprangers, J.J.H. Paulides, B.L.J. Gysen, and E.A. Lomonova, "Magnetic Saturation in Semi-Analytical Harmonic 
Modeling for Electric Machine Analysis," IEEE Trans. Magn., vol. 52, no. 2, Art. ID. 8100410, Feb. 2016.

18. Z. Djelloul-Khedda, K. Boughrara, F. Dubas, and R. Ibtiouen, "Nonlinear Analytical Prediction of Magnetic Field and Electromagnetic Performances in Switched Reluctance Machines," IEEE Trans. Magn., vol. 53, no. 7, Art. ID 8107311, Jul. 2017.

19. Z. Djelloul-Khedda, K. Boughrara, F. Dubas, A. Kechroud, and B. Souleyman, "Semi-Analytical Magnetic Field Predicting in Many Structures of Permanent-Magnet Synchronous Machines Considering the Iron Permeability," IEEE Trans. Magn., vol. 54, no. 7, Art. ID 8103921, Jul. 2018.

20. L. Roubache, K. Boughrara, F. Dubas, and R. Ibtiouen, "Elementary subdomain technique for magnetic field calculation in rotating electrical machines with local saturation effect," COMPEL - The international journal for computation and mathematics in electrical and electronic engineering, Jun. 2018, doi: 10.1108/COMPEL-11-2017-0481.

21. L. Roubache, K. Boughrara, F. Dubas, and R. Ibtiouen, "Technique en Sous-Domaines Élementaires dans les Machines Asynchrones à Cage d'Écureuil : Saturation Magnétique Locale \& Courants de Foucault dans les Barres," Symposium du Génie électrique (SGE), 2018, pp. 1-7.

22. D. Meeker, "Finite Element Method Magnetics." [Online]. Available: http://www.femm.info.

23. S.J. Farlow, Partial Differential Equations for Scientists and Engineers. Courier Corporation, 1993.

24. H. Hannoun, "Etude et mise en oeuvre de lois de commande de la machine à réluctance variable à double saillance," thesis, Paris 11 , 2008 . 